\section{LAS PROHIBICIONES HISTÓRICAS DE LA FIESTA DE LOS TOROS}

\author{
Álvaro Luis Sánchez-Ocaña Vara \\ Universidad de Salamanca \\ alvarosov@hotmail.com
}

\section{HISTORICAL BANS ON BULLFIGHTING}

Cómo citar este artículo/Citation: Sánchez-Ocaña Vara, A. L. (2013). "Las prohibiciones históricas de la fiesta de los toros". Arbor, 189 (763): a074. doi: http://dx.doi.org/10.3989/ arbor.2013.763n5011

Recibido: 1 octubre 2012. Aceptado: 18 junio 2013.

RESUMEN: En el siguiente artículo trataremos de analizar en el tiempo las diferentes prohibiciones que se han producido a lo largo de la historia contra la que, para García Lorca, es la fiesta más culta del mundo.

Prohibiciones de las que, unas más severas que otras, la Fiesta siempre ha logrado salir adelante y las cuales hemos de tenerlas en cuenta en los difíciles tiempos actuales en que esta se encuentra.

Lo decía Ortega y Gasset: "No puede comprenderse bien la historia de España sin haber construido la historia de las corridas de toros". Por tanto, el análisis que a continuación se detalla no hace más que resaltar la enorme importancia que, desde tiempos inmemoriales, esta tradición ha tenido para el pueblo español y, a pesar de las prohibiciones, no consiguieron acabar con su celebración debido a su profundo arraigo en las raíces de España.

PALABRAS CLAVE: Fiesta; Toros; Prohibiciones; Historia; Iglesia; Autoridad civil; España.
Copyright: (C) 2013 CSIC. Este es un artículo de acceso abierto distribuido bajo los términos de la licencia Creative Commons Attribution-Non Commercial (by-nc) Spain 3.0.

ABSTRACT: This article looks at the various bans on bullfighting -which Garcia Lorca described as the world's most education celebration- that have been imposed in the past.

Despite these prohibitions, some of which were more severe than others, bullfighting has always managed to prevail, and this fact needs to be taken into account in today's difficult times for this tradition.

Ortega y Gasset said: "It is impossible to understand the history of Spain properly without first constructing the history of bullfighting." Therefore, the detailed analysis that follows merely highlights the enormous importance, since time immemorial, this tradition has had for the Spanish people and that, despite the prohibitions, they continued celebrating, because it is so deeply rooted in Spain.

KEYWORDS: Fiesta; Bulls; Prohibitions; History; Church; Civil authority; Spain. 


\section{PRIMERAS DISPOSICIONES CONTRA LA FIESTA DE LOS TOROS}

La expansión y difusión de los espectáculos taurinos, ya consolidados a partir del siglo XIII en aquellos territorios de la península bajo dominio cristiano, va íntimamente ligada a los continuos intentos de prohibir los mismos.

Así, en el mismo siglo XIII encontramos lo que podemos denominar la primera disposición (no prohibitiva, pues es meramente condenatoria) contra la celebración de estos espectáculos. Pero debemos matizar este punto, ya que el texto del que hablamos no es otro que el Código de las Siete Partidas, del monarca castellano Alfonso X el Sabio (1221-1284). Ahora bien, este documento hemos de entenderlo en el contexto en que se fraguó, dentro de las pautas del Concilio de la Edad Media o, lo que es lo mismo, el IV Concilio Ecuménico de Letrán (1215), que en los cánones 1417 se encarga de las irregularidades del clero, como la incontinencia, ebriedad, caza, asistencia a farsas y exhibiciones histriónicas.

Dentro de las exhibiciones podemos incluir los espectáculos taurinos y es por ello, por ser considerados estos como espectáculo, como juego heredado de los antiguos ludi romanos, por lo que son condenados en las Siete Partidas.

Veamos pues, qué dice el texto sobre los toros. En la Partida I, Título V, Ley 57, se establece lo siguiente:

Que los perlados non deven deyr a ver los juegos, ni jugar tablas nin dados, nin otros juegos, que los sacassen del sossegamiento...e porenden no deven yr a ver los juegos: assi como alançar, o bohordar, o lidiar los Toros, o otras bestias bravas, nin yr a ver los que lidian... (Badorrey Martín, 2009, 3-4).

Vemos como la "prohibición" si podemos denominarla de tal manera, únicamente va dirigida al clero, quedando excluidos los hombres de a pie, a los que también condena, especialmente a los "toreros" de la época:

Como aquel que lidia con bestia brava por precio quel den non puede ser bozero por otro, si non en casos señalados...non puede ser abogado por otro, ningund ome que recibiesse precio, por lidiar con alguna bestia... (Tercera Partida, Título VI, Ley 4) (Badorrey Martín, 2002, 87-94).

Como vemos, solo es condenatoria a aquellos que lidian a cambio de dinero, pero entendido esto dentro de la moralidad de la época, donde aquel capaz de lidiar contra bestia brava a cambio de dinero, su ética era cuestionable y, cuanto menos, era considerado una persona indigna y no honorable.
Por tanto, podemos considerar que las corridas de toros eran unas diversiones permitidas a los laicos, pero prohibidas a los clérigos, por la mera razón de considerarlas las autoridades eclesiásticas impropias para su estado.

Relacionado con todo ello, tres siglos más tarde, encontramos disposiciones provenientes de diferentes sínodos españoles, pudiendo destacar el de Burgos de 1503, el de Sevilla de 1512, el de Orense de 1539 o el de Oviedo celebrado en el año 1553 (Badorrey Martín, 2009, 4-6). Todos ellos comparten el mismo trasfondo, la prohibición hacia los clérigos de participar o ver corridas de toros, además de otras actividades consideradas impropias para ellos, como bailes, cantes, etc.

\section{EL CONCILIO DE TRENTO (1545-1563)}

Como respuesta a las reformas protestantes que, desde principios de siglo se expandían a lo largo y ancho de Europa, la Iglesia decidió atajar el problema mediante la denominada Contrarreforma, la cual tuvo en el Concilio de Trento su máximo exponente. Aunque pareciese novedoso, en él no se trataron más que los problemas que el clero arrastraba desde la Baja Edad Media, ya señalados anteriormente y, entre ellos, el problema de los toros, contra el que algunos obispos españoles expresaron su deseo de prohibirlas. No obstante, en el Concilio no se determinó nada al respecto, quedando bajo arbitrio de los obispos españoles tal decisión.

Ya en la península, únicamente en tres concilios se trataría el tema de la prohibición de las corridas de toros: Toledo, Granada y Zaragoza en 1565 y 1566. Respecto al tema que nos interesa, las prohibiciones de los toros, no son muy distintas a las disposiciones de sínodos españoles promulgadas apenas medio siglo antes, "ningún clérigo de orden sacro ande en el cosso ni salga dissimulado a toros ni a juego de cañas ni a otro juego público...". (Badorrey Martín, 2009, 9-12). Vemos pues, como se seguía condenando la participación del clero en los toros, entendidos estos como juegos, tal y como se venía haciendo desde las Partidas del rey Sabio tres siglos atrás.

\section{LOS TOROS EN LAS CORTES DE CASTILLA}

El tema de las prohibiciones no vino únicamente de la mano de la Iglesia y, en los mismos años que se sucedieron las disposiciones conciliares anteriores, se fue desarrollando una campaña antitaurina que llegó incluso a las mismas Cortes de Castilla. 
En las Cortes de Valladolid de 1555 se acordó pedir al rey que "fuera servido de mandar que no se corran los dichos toros, o que se dé alguna orden para que si se corrieran no hagan tantos daños".

En las Cortes de Madrid de 1567 (mismo año que se publicará la bula de Pio V, como veremos a continuación), se vuelve a poner sobre la mesa el mismo asunto visto en Valladolid, donde se pedía al monarca "que en estos reynos no se corran los dichos toros".

A lo anterior, el monarca Felipe II contestó:

A esto vos respondemos que en quanto al daño que los toros que se corren hazen, los Corregidores y Justicias lo provean y prevengan de manera que aquel se escuse de quanto se pudiere, y que en quanto al correr de los dichos toros, esta es una antigua y general costumbre destos nuestros Reynos, y para la quitar será menester mirar más en ello, y ansí por agora no conviene se haga novedad.

En 1587 se discute nuevamente el tema en las Cortes del citado año, pero esta vez, atacando a los espectáculos taurinos con alicientes económicos (que será una constante en el siglo XVIII debido a la influencia de la llustración).

El resultado de todo ello fue negativo para las proposiciones antitaurinas, pues las corridas de toros siguieron celebrándose. No obstante, en esos años recibiría la fiesta la mayor y más dura de las prohibiciones por parte de la Iglesia en toda su historia, las cuales a continuación analizaremos (Cossío, 2007, 516-519).

Es interesante resaltar que la prohibición dio el salto a Nueva España y, en Perú, a partir de 1551, se decretó la prohibición de los clérigos a ver o participar en las corridas de toros. Pero no solo en Perú, sino también en Nueva España (México) fue prohibida esta práctica. Así, se celebraron hasta cuatro concilios provinciales en 1555, 1565, 1585 y 1769 (este último en tiempos de Carlos III), donde se reiteraba lo mismo que se analizó en España en los concilios postridentinos, la definitiva regulación de los aspectos relativos a la vida y honestidad de los clérigos, prohibiendo, como se ha dicho, la asistencia y participación de estos en las corridas de toros (Badorrey Martín, 2011, 485-491).

\section{LAS PROHIBICIONES PONTIFICIAS}

Pues bien, en el año 1567 el pontífice Pío V promulgó la bula De Salute Gregis, con la cual excomulgaba ipso facto a todos los príncipes cristianos que celebrasen corridas de toros en sus reinos. Pese a la magnitud de la disposición, en España, bajo Felipe II (rey que, aunque no manifestara su amor a los toros, si lo tenía hacia su pueblo) continuaron organizándose corridas de toros.

Creo conveniente traer a colación un documento, extraído de la obra de Santiago Esteras Gil, La fiesta de los toros y sus tristes verdades, que dice lo siguiente:

En un artículo de $A B C$ aparecido en 1960 con el título 'La prohibición de las corridas de toros'... se hablaba de Felipe II en relación con la prohibición contenida en la Bula Papal.

-Decidnos - dijo el Rey dirigiéndose a los nobles-. ¿Qué dispone la Bula?

-Prohíbe señor que se corran los toros.

-Pues a fe que os podéis divertir sin contrariar la decisión de nuestro Santo Padre.

- ¿Y cómo señor?

-Pues corriendo vacas. (Esteras Gil, 1962, 45).

Siguiendo con las disposiciones papales, seguiría a la de Pío V la de su sucesor, Gregorio XIII en 1575, con la promulgación de la bula Exponis nobis, en la cual levantaba la excomunión inmediata de su predecesor ${ }^{1}$, dejando la excomunión únicamente a los clérigos que participasen en las corridas de toros. Además, mandaba que no se celebrasen corridas en días de fiestas, así como se evitaran a toda costa las desgracias.

El nuevo pontífice, Sixto $\mathrm{V}$, volverá de nuevo a poner en vigor la bula de Pío $\mathrm{V}$ y, finalmente, el Papa Clemente VIII, en 1596, con la bula Suscepti numeris, será quien liberará definitivamente de condenas a los participantes y organizadores de las corridas de toros.

De la pugna entre la Santa Sede y la Monarquía española se llegó a la conclusión de que no se corrieran toros en días de ferias, por evitar desgracias debido a la aglomeración; ahora bien, esto hemos de entenderlo bajo el contexto eclesiástico de que esos días eran religiosos y, por tanto, la ausencia de corridas los haría brillar con luz propia (Asín, 2008, 73-78).

\section{LAS PROHIBICIONES CIVILES DEL SIGLO XVIII}

De unos monarcas claramente taurinos como fueron los Austrias, el siglo XVIII da paso a su antítesis, los Borbones que, fruto de su tradición ilustrada francesa, no compartieron la afición de sus predecesores por la fiesta de los toros.

En el siglo XVIII, siglo en que se afianza el espectáculo, sufre las mayores críticas, siendo sus máximos detractores los ilustrados, quienes se basan en las ne- 
fastas consecuencias de la celebración de corridas de toros para la economía del país (disminución del ganado boyal, encarecimiento de las carnes, etc.), así como el absentismo laboral provocado y la imagen negativa que España transmitía al extranjero (Badorrey Martín, 2009, 26).

Se inicia el siglo ilustrado con la prohibición de celebrar corridas de toros en Madrid y alrededores, aprobada por Felipe $V$ en 1704. Esta prohibición estuvo vigente hasta 1725 , año en que el propio rey, por razones desconocidas, volvió a restablecer la celebración de corridas de toros.

Fernando VI prohibiría nuevamente la fiesta de los toros en 1754, con la excepción de cuando se organizase con fines benéficos, aunque dicha prohibición sólo duró un lustro, hasta 1759.

Sin embargo, las disposiciones más serias y de mayor relevancia serán las dictadas por Carlos III y Carlos IV. Así, Carlos III, influenciado por el Conde de Aranda, a través de una Real Orden de 1778 prohíbe nuevas concesiones de fiestas de toros y "mandando que el Consejo vea de subrogar con otros arbitrios las que están concedidas con fines piadosos". Pero el paso definitivo será la Real Pragmática Sanción de 1785, por la que prohíbe "las fiestas de toros de muerte en todos los pueblos del Reyno, a excepción de los en que hubiere concesión perpetua o temporal con destino público de sus productos útil o piadoso...". Pese a ello, se continuaron festejando corridas, por lo que el mismo rey tuvo que dictar una Real Orden en 1786 en la que ordenaba que cesasen todas las licencias, manteniendo como excepción la de Madrid.

Las Reales Ordenes y la pragmática continuaban sin cumplirse, ante lo cual, su sucesor, Carlos IV, primero con la promulgación de una real provisión en 1790 (donde prohibía correr novillos y toros de cuerda por las calles) y, posteriormente, mediante Real Pragmática de 1805, "prohíbe absolutamente en todo el Reyno, sin excepción de la Corte, las fiestas de los toros y novillos de muerte". (Fernández de Gatta, 2009b, 7-13). Debemos señalar que el monarca hispano actuó bajo la influencia de Godoy, el Príncipe de la Paz, quien en sus memorias escribe lo siguiente:

Al mismo año de 1805 pertenece la abolición de las corridas de toros y novillos de muerte... Si bien tuve mucha parte en la adopción de esta reforma, no por esto fue obra de capricho mío. Este asunto fue llevado al Consejo de Castilla, y tratado en él y madurado largamente. Arribados mis enemigos a la plenitud del poder, restablecieron estos espectáculos sangrientos... No se dio pan a nadie, pero se die- ron toros... las desdichadas plebes se creyeron bien pagadas (Vidart, 1887, 94).

En esta línea, el más firme detractor de los ilustrados fue José Vargas Ponce quien, en su obra Disertación sobre las corridas de toros, nos señala el propósito de la misma:

La presente, pues, tendrá por objeto y única materia las corridas de toros que se daban en España porque son frecuentes las equivocaciones acerca de su origen y multiplicados y graves efectos, como ellas lo eran por nuestra desgracia; y de ponerlas en su verdadera luz me persuado que, haciendo algo por nuestra ilustración y desengaño, abogo la causa de la Humanidad.

Crítica absoluta contra la celebración del espectáculo nacional desde sus mismos orígenes; para el autor, su celebración no produce otra cosa que "una juventud atolondrada, falta de educación como de luces y experiencias, los preocupados que la encarecieron sin hacer uso de la facultad de pensar, los viciosos por hábito, hambrientos siempre de desórdenes y, en una palabra, la hez de todas las jerarquías (Vargas Ponce, 1807).

Sin embargo, las palabras de Vargas Ponce, así como de numerosos escritores dedicados a tratar sobre la fiesta de los toros durante los siglos XVIII y XIX han sido desmontadas así como demostrado que sus escritos no eran sino una falacia fruto de los intereses de determinados grupos contrarios a la Fiesta (García Añoveros, 2011). En la misma línea, también se ha tratado el tema de la licitud del espectáculo entre los moralistas y escritores de la época anterior, la de los Austrias, ahondando más si cabe la licitud moral de las corridas de toros, desarmando por completo a Vargas Ponce, quien falsea documentos, recorta textos a su antojo e interés, etc. (García Añoveros, 2007).

\section{DEBATE Y PROHIBICIONES EN LOS SIGLOS XIX Y XX}

No debe extrañarnos cómo el asunto de los toros llegara a las Cortes de Cádiz, iniciadas en 1810 hasta 1812. Creo conveniente señalar cómo esta ciudad podría denominarse entonces como "antitaurina", pues ya desde el siglo XVIII sufre un fuerte acoso por parte de la iglesia gaditana. Incluso en el año 1780 se publicó el "Auto de buen gobierno... por el excelentísimo Señor Capitán General Gobernador de Cádiz, previniendo... que no se corran por las calles bacas ni novillos con guindaleta por las desgracias que puedan ocasionar". Recordemos que no será hasta 1790 cuando el rey Carlos III dictará la Pragmática de la prohibición de correr novillos y toros, por tanto, encontramos que ya, diez años antes, la ciudad gaditana se había adelantado a la Pragmática real. 
En 1813, como consecuencia de un incidente producido en la plaza de toros de Cádiz (lo que muestra que se seguían practicando corridas de toros), provocó la nueva reacción municipal contra la fiesta. El problema estaba en que, el propietario de la plaza, Don Francisco de la Iglesia Darrac, había comprometido las ganancias de las corridas en una contrata con el gobierno; por tanto, pese a la petición popular, la plaza de Cádiz quedó dispensada de la prohibición de las corridas de toros por el tiempo necesario hasta cumplir dicha contrata (Orgambides Gómez, 2003).

Destacar que, como hemos visto, siendo el gobierno español quien había prohibido (o no cesaba en su afán de hacerlo) las fiestas de los toros, José I Bonaparte, en su breve reinado en la península, favoreció las mismas, siendo su proclamación como rey celebrada con dos corridas de toros.

Por tanto, una vez finalizada la Guerra de la Independencia, aunque el Decreto de 1805 nunca fue derogado, en la práctica, como se ha visto, no tenía aplicación alguna y no volvió a tenerse en cuenta. A partir de entonces no encontramos más tentativas de prohibir los toros (hasta la prohibición actual de Cataluña) y la actitud hacia la misma fue de "simple tolerancia" (Badorrey Martín, 2009, 41-43).

Esta actitud de tolerancia aparece claramente plasmada en la Instrucción de los Subdelegados de Fomento, publicada por Javier Burgos en 1833, donde establece:

... De los espectáculos mencionados hay uno en que arriesgan hombres, se destruyen animales inútiles... La autoridad administrativa debe indirectamente acelerar este beneficio, rehusando a esta clase de espectáculos otra protección que una simple tolerancia...

Sin embargo, como todas las disposiciones prohibitivas anteriores, no fue tenido en cuenta, y menos aún a principios del XIX cuando el espectáculo estaba arraigándose aún más en el pueblo y comenzaba a regularse de forma oficial.

Pese a predominar la actitud tolerante por parte del sector antitaurino español, el siglo XIX daría lugar a más controversias. Así, en la década de los sesenta, debido a la muerte de Pepete, el tema fue de nuevo tratado en el Parlamento.

Muy a tener en cuenta sería una proposición de ley del año 1877, del marqués de San Carlos, donde se abogaba por la supresión de las corridas de toros, así como "...las carreras, lidias y funciones de reses vacunas dentro de las poblaciones", como también "las algaradas o diversiones de acosar toros con vara larga en campo abierto o en el monte"; en la misma, como puede observarse, no solo se refería a las corridas de toros sino a todos los festejos taurinos; se prohibían la construcción de nuevas plazas de toros y la reedificación de las que se encontrasen derruidas, así como sería potestad del Gobierno la supresión de las corridas de toros de muerte dentro de un plazo de tiempo prudencial. Ocho años más tarde, el marqués de San Carlos volvió a la carga de nuevo, siendo ambas veces la propuesta retirada (Fernández de Gatta, 2009b, 80-81).

De nuevo, debido a la grave cogida de Frascuelo en 1876 y a la muerte de el Espartero de 1894, se levantó un nuevo revuelo contra la fiesta; incluso se presentó ante el Congreso una enésima propuesta contra su prohibición; propuesta que, como sus antecesoras, corrió su misma suerte (Cossío, 2007, 619-622).

Un último hito importante en contra de la fiesta de los toros serían las celebraciones producidas, a partir de 1875, en la ciudad de Cádiz, bajo el mecenazgo de la Sociedad Protectora de los Animales de Cádiz, donde en el citado año se celebró un concurso sobre trabajos contrarios a las corridas de toros. Fueron muchos los trabajos escritos, sin embargo, lo que nos llama la atención es que la misma sociedad elevó una "Instancia a S.M. el Rey D. Alfonso XII en demanda de que suprimiese las corridas de toros acordadas para celebrar su enlace con S.S.I. Ia Archiduquesa María Cristina de Austria" (Orgambides Gómez, 2003).

El siglo XX será muy diferente en cuanto a prohibiciones se refiere, pues apenas encontramos alguna a lo largo del mismo. Aunque el siglo comenzará con la prohibición de las corridas de toros mediante Real Orden de 1900, repitiéndose en 1904 y 1908, la fiesta seguiría adelante, produciéndose a lo largo de este siglo su institucionalización jurídica, pues verán a la luz los diferentes reglamentos oficiales que regulan los toros.

Es interesante resaltar la Real Orden de junio de 1928, por la que "quedan absolutamente prohibidas las capeas, cualquiera que sean las condiciones y edad del ganado que en ellas hubiere de lidiarse" (Fernández de Gatta, 2009b, 88).

Durante el breve periodo de tiempo de la Segunda República Española (1931-36), se promulgó una Orden (1931 y 1932) que trataría de terminar con esta clase de espectáculos, así como el Reglamento de Policía y Espectáculos Públicos de 1935. El gobierno republicano basaba su prohibición en "razones de humanidad y porque el Gobierno de la República tiene 
que cumplir una misión de cultura"; también autorizaba a los Gobernadores Civiles a destituir a aquellos alcaldes en cuyas localidades se celebrasen corridas de toros. Sin embargo, a partir de enero de 1932, una nueva disposición permitiría celebrar corridas de toros y novillos en plazas provisionales, siempre que la lidia corriese a cargo de toreros profesionales, prohibiendo "en absoluto que se corran toros y vaquillas ensogadas o en libertad por las calles y plazas de las poblaciones".

A su vez, el mencionado Reglamento de Policía y Espectáculos Públicos reiteraba la disposición de dos años antes, en la que "queda en absoluto prohibido que sean corridos toros, novillos ni vaquillas, ensogados o en libertad, por las cales y plazas de las poblaciones" (Claramunt López, 2006).

Incluso en el reglamento de 1962, el "Texto Refundido del nuevo Reglamento de Espectáculos Taurinos", se prohíbe que se "corran toros o vaquillas ensogados o en libertad por calles y plazas de las poblaciones", permitiendo exclusivamente los encierros de Pamplona, debido a su carácter tradicional, así como otros de características similares, como los de Cuéllar, en Segovia, o Ciudad Rodrigo, en Salamanca (Fernández de Gatta, 2009b, 90-96).

\section{LA POLÉMICA ACTUAL: PROHIBICIÓN DE LAS CORRIDAS DE TOROS EN CATALUÑA}

Como por todos es bien conocido, tras cincuenta años de apoteosis de la Fiesta en nuestro país, hemos de hablar, por desgracia, de la iniciativa catalana, la cual ha conseguido prohibir las corridas de toros en esta comunidad a partir de este año en que nos encontramos.

Hemos de señalar que no ha sido la única iniciativa llevada a cabo, puesto que a la actual le precedieron otras en 2004 y 2005; no obstante, será la Proposición de Ley sobre la modificación de la Ley de Protección de los Animales, a expensas de la ILP catalana, de noviembre de 2008 la que consiga terminar con las corridas de toros en Cataluña. Dicha proposición fue aceptada por el Pleno del Parlamento en diciembre del 2009, iniciándose la correspondiente tramitación, que terminó en 2010 con la votación en el Pleno, con 68 votos a favor por 55 en contra, y 9 abstenciones.

¿Cómo es posible que, en un país de denotada tradición taurina como el nuestro, hayamos llegado a esto? Buena culpa de ello la tiene la ausencia en la Carta Magna de un artículo sobre la fiesta nacional, ya que la materia relativa a la Fiesta de los Toros (espec- táculos públicos, en general) no aparece ni como competencia exclusiva del Estado, ni entre las competencias que puedan asumir las Comunidades Autónomas (arts. 148 y 149). Al no mencionarse los espectáculos taurinos en el art. 149, los Estatutos de Autonomía podían asumir la competencia correspondiente, materia que no fue asumida homogéneamente por todas las Comunidades. Así, debido a ello, a la multiplicidad de Reglamentos existentes, las denominadas tauroautonomías, (Ramón Fernández, 1987; 2011), podemos hablar de una verdadera encrucijada jurídica de la Fiesta. (Fernández de Gatta Sánchez, 2011).

Ahora bien, de nosotros depende, no sólo taurinos, sino defensores de la libertad en un estado teóricamente democrático, de aunarnos y no permitir que el efecto de lo acontecido en Cataluña salpique otros puntos de nuestro país aunque, por desgracia, esto no es así, puesto que a día de hoy tenemos constancia de que el próximo año una plaza como San Sebastián no celebrará toros, ya que Bildu, el gobierno local, no ha renovado la contrata con la plaza de Illumbe para la próxima temporada.

Como bien sabemos, lo que en Cataluña comenzó con una ley contra el maltrato de los animales, estaba enfundada en un matiz totalmente político, con afán de eliminar lo español, lo nacional de Cataluña como es la fiesta de los toros. Si no fuera así, ¿de qué manera podríamos entender que, a un mismo tiempo que se prohíben las corridas de toros, se blinda el espectáculo popular de los correbous? Un espectáculo en el que, por cierto, los animales sufren un estrés similar o mayor que en la plaza y que, no contentos con ello, se ha admitido hace relativamente pocos días una propuesta para que el tiempo de los toros embolados sea mayor y, por ende, mayor el sufrimiento del animal, un animal cuya protección fue el eje de partida para la prohibición de las corridas de toros.

¿Se habrán parado a pensar los catalanes abolicionistas las consecuencias que esta prohibición va a acarrear para su economía? Al prohibir las corridas de toros, la Generalitat se enfrenta a dos cuestiones: por un lado el daño emergente $y$, por otro, el lucro cesante.

Teniendo en cuenta que la Barceloneta es uno de los cosos con mayor capacidad de todo el país y que en la temporada 2007 pasaron por sus asientos más de 111.000 espectadores, a una media de 40 euros localidad, nos encontraríamos con una facturación anual por parte de la empresa de casi cuatro millones y medio de euros. Por tanto, como daño emergente, la Generalitat habría de abonar a la empresa 
daños tales como indemnizaciones por despido de los trabajadores, la cláusula de rescisión del contrato de la propiedad con la empresa gestora del coso, entre otros (esto supondría entre 50 y 150 millones de euros). Por otro lado, en cuanto a lucro cesante, se refiere a los derechos individuales que se verán afectados por la prohibición, contabilizando estos a 99 años vista, según el derecho civil catalán; nos encontramos entonces que, a 4 millones de euros anuales, multiplicados por 99 años, son casi $400 \mathrm{mi}-$ llones de euros que la Generalitat ha de abonar a los perjudicados. $\mathrm{O}$, lo que es lo mismo, cada uno de los siete millones de catalanes, tendrán que pagar unos 57 euros para sufragar el coste que la prohibición de las corridas de toros ha supuesto para su gobierno y el bolsillo de los ciudadanos.

Esperanzadora es, qué duda cabe, la iniciativa popular surgida desde al taurinismo a raíz de la mencionada prohibición y que, hilando todo lo anterior, no intenta sino aunar las tan dispares competencias normativas de la Fiesta de los Toros. En lugar de hablar de diferentes reglamentos para las comunidades que así lo contemplan, ¿por qué no hablar de una única Ley Taurina que legislase todo? (Hurtado González, 2012). Por tanto, iniciativa cuyo objetivo último es la declaración de la Fiesta como Bien de Interés Cultural para, de esa manera, frenar el despropósito catalán así como evitarlos en un futuro próximo.

\section{CONCLUSIÓN}

Por tanto, hemos visto cómo han sido múltiples y muy serias las tentativas de prohibir la Fiesta desde la Edad Media hasta nuestros días. Más de setecientos años de propuestas de ley, reales decretos, pragmáticas... que no han hecho sino reforzar una fiesta tan significativa para la historia y cultura de nuestro país. Decía Ramón Pérez de Ayala que "el nacimiento de la Fiesta coincide con el nacimiento de la nacionalidad española y con la lengua de Castilla... así pues, las corridas de toros son una cosa tan nuestra, tan obligada por la naturaleza y la historia como el habla que hablamos".

Si el pueblo español ha superado las tentativas papales en el XVI, reales a finales del XVIII y principios del XIX, ¿se va a dar por vencido porque una minoría pretenda suprimir esta Fiesta que tanto significa para España? ¿Estamos dispuestos a perder algo tan nuestro, tan arraigado en nuestra cultura?

Terminaremos el artículo como lo hemos empezado, esta vez con palabras del genio García Lorca, para quien "el toreo es probablemente la riqueza poética y vital de España, increíblemente desaprovechada por los escritores y artistas, debido principalmente a una falsa educación pedagógica que nos han dado y que hemos sido los hombres de mi generación los primeros en rechazar; creo que los toros es la fiesta más culta que hay en el mundo".

Por último, a aquellos deseosos de prohibir una Fiesta tan culta y tan nuestra, les diría aquello del filósofo Francis Wolf: "a quienes son ajenos al mundo de los toros, esperando que vislumbren la universalidad de un arte singular...".

\section{NOTAS}

1 Según Vidart, esto se consiguió gracias a las insistencias de Felipe II (Vídart, 1887). 
Asin, E. (2008). Los toros josefinos: corridas de toros en la Guerra de la Independencia bajo el reinado de José I Bonaparte, 1808-1814. Zaragoza: Institución Fernando el Católico.

Badorrey Martín, B. (2011). "Las prohibiciones canónicas de las fiestas de toros en Nueva España". Instituto de Investigaciones Jurídicas, Boletín Mexicano de Derecho Comparado, núm. 131, pp. 477-505.

Badorrey Martín, B. (2002). “Primeras disposiciones jurídicas sobre las fiestas de toros". En VV. AA., La Fiesta de los Toros ante el Derecho. Madrid: Ed. UTAE.

Badorrey Martín, B. (2009). “Principales prohibiciones canónicas y civiles de las corridas de toros". Provincia, núm. 22.

Claramunt López, F. (2006). República y toros (España, 1931-1936). Madrid: Ed. Egartorre.

Cossío, J. M. de (2007). Los Toros, vol. 6. Barcelona: Espasa Calpe.

Esteras Gil, S. (1962). La fiesta de los toros y sus tristes verdades. Logroño: T.C. Casals.
Fernández de Gatta, D. (2009a). “El régimen jurídico de la fiesta de los toros: de las prohibiciones históricas a los reglamentos autonómicos del siglo XXI". En El Consultor de los Ayuntamientos, núm. 24, pp. 3614-3634.

Fernández de Gatta, D. (2009b). El régimen jurídico de los festejos taurinos populares y tradicionales. Salamanca: Globalia Ediciones Anthema.

Fernández de Gatta, D. (2010). “La inconstitucionalidad de la prohibición catalana de las corridas de toros". Centro Etnográfico del Toro de Lidia (ITACYL).

Fernández de Gatta, D. (2011). "La encrucijada jurídica de la fiesta de los toros". Diario la Ley, no 7678.

Fernández Rodríguez, T. R. (1987). Reglamentación de las corridas de toros. Madrid: Ed. Espasa Calpe.

Fernández Rodríguez, T. R. (2011). “EI Reglamento Taurino: ¿unificación?”. En Encuentros Internacionales de Derecho Taurino, segundo tercio: los juristas y la tauromaquia. Valencia: Tirant Lo Blanch.
García Añoveros, J. M. (2007). El hechizo de los españoles. La lidia de los toros en los siglos XVI y XVII en España e Hispanoamérica. Historia, sociedad, cultura, religión, derecho, ética. Madrid: Unión de Bibliófilos Taurinos.

García Añoveros, J. M. (2011). Los ilustrados y los toros. Madrid: Unión de Bibliófilos Taurinos.

Hurtado González, L. (2012). “Cuestiones competenciales sobre la fiesta de los toros: a propósito de su posible declaración legal como bien de interés cultural". Revista Andaluza de Administración Pública, no 83, mayo-agosto 2012, pp. 12-47.

Orgambides Gómez, F. J. (2003). “Cádiz antitaurino, siglos XVIII y XIX". En II Centenario de Paquiro (1805-2005)- I Congreso Internacional Taurino, Cádiz [http:// www.chiclana.es/paquiro. Consultado el 14 de febrero de 2012].

Vargas Ponce, J. de (1807). Disertación sobre las corridas de toros.

Vidart, L. (1887). Las corridas de toros y otras diversiones populares. 